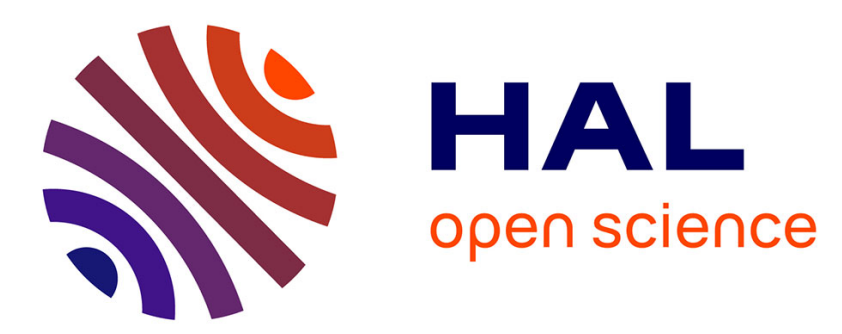

\title{
Importance of the Antenna Model to Assess GNSS Multipath in Airport Environments
}

Capucine Amielh, Alexandre Chabory, Christophe Macabiau, Laurent Azoulai

\section{To cite this version:}

Capucine Amielh, Alexandre Chabory, Christophe Macabiau, Laurent Azoulai. Importance of the Antenna Model to Assess GNSS Multipath in Airport Environments. USNC-URSI Radio Science Meeting 2018, Jul 2018, Boston, United States. pp.109-110. hal-02005017

\section{HAL Id: hal-02005017 https://hal-enac.archives-ouvertes.fr/hal-02005017}

Submitted on 4 Feb 2019

HAL is a multi-disciplinary open access archive for the deposit and dissemination of scientific research documents, whether they are published or not. The documents may come from teaching and research institutions in France or abroad, or from public or private research centers.
L'archive ouverte pluridisciplinaire HAL, est destinée au dépôt et à la diffusion de documents scientifiques de niveau recherche, publiés ou non, émanant des établissements d'enseignement et de recherche français ou étrangers, des laboratoires publics ou privés. 


\section{Importance of the Antenna Model to Assess GNSS Multipath in Airport Environments}

\author{
C. Amielh \\ ENAC TELECOM \\ Toulouse, France \\ capucine.amielh@enac.fr
}

\author{
A. Chabory \\ ENAC TELECOM \\ Toulouse, France \\ alexandre.chabory@enac.fr
}

\author{
C. Macabiau \\ ENAC TELECOM \\ Toulouse, France \\ christophe.macabiau@enac.fr
}

L. Azoulai
Airbus

Toulouse, France

laurent.azoulai@airbus.com

\begin{abstract}
For GNSS systems, the gain, phase and group-delay patterns of the receiver antenna have an impact on the pseudoranges, i.e. the apparent distances to the satellites estimated by the receiver. In the presence of multipath, this impact is difficult to assess because multipath and antenna effects are mixed. In this article, these sources of pseudo-range error are analyzed by means of simulations for an aircraft moving at the surface of an airport. For the simulations, we rely on a hybrid statisticaldeterministic GNSS multipath simulator combined with a receiver simulator. Various antenna models are tested, e.g. an ideal isotropic antenna and a realistic antenna mounted on an aircraft, with and without the phase and group-delay patterns.

Index Terms-Multipath, aircraft, antenna, phase, group delay
\end{abstract}

\section{INTRODUCTION}

When navigating on the airport surface, aircraft ground position and ground velocity can be estimated using a large variety of sensors, such as Global Navigation Satellite System (GNSS). However, measurements from this sensor are affected by signal blockage and multipath. In [1], a deterministic approach to simulate GNSS multipath for airport navigation has been proposed. This approach has been statistically enhanced by introducing uncertainties in the 3D environment [2]. Up to now, in this model, the antenna has only been accounted by its gain pattern.

In this publication, we aim at improving this antenna model by considering far-field gain, phase and group-delay patterns simulated with Feko. For the GPS L1 frequency band, the influence of the antenna phase and group delay variations on the simulated multipath pseudo-range errors are then analyzed and compared with measurements.

In Section II, the method for computing the multipath pseudorange error is presented. In Section III, the proposed antenna models are detailed. In Section IV, simulation and measurement results are discussed.

\section{GNSS Multipath Model For Aircraft Surface NAVIGATION}

For a given aircraft trajectory and satellite position, the computation of the multipath is based on a deterministic electromagnetic method applied to an airport scene with statistical uncertainties (Fig. 1). The elements in the scene, e.g. airport buildings, are described by means of a polygonal mesh. First and second-order interactions are determined as follows.

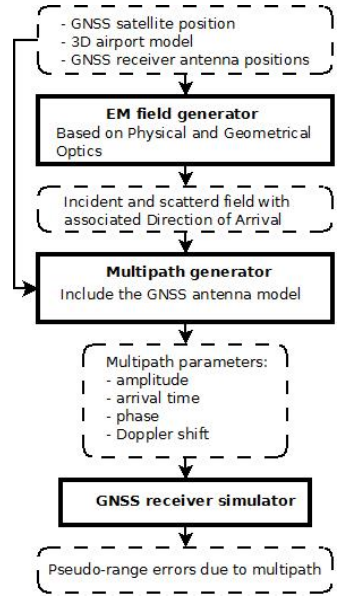

Fig. 1: Multipath ranging error model

For first-order interactions, each illuminated facet yields a scattered field via Physical Optics (PO). For second-order interactions, Geometrical Optics (GO) is used to determine the illuminated facets and the associated incident fields. Then, the scattering is obtained with $\mathrm{PO}$ as for first-order interactions. The reflection over the ground is accounted via the image theorem.

After passing through the receiver antenna, each scattered field yields one multipath, characterized by an amplitude, a phase, a delay and a Doppler shift. Amplitude and phase are directly related to the scattered field while the delay and Doppler shift are assessed geometrically from the satellite position and aircraft trajectory. Finally, the pseudo-range error is determined from the multipath parameters via a GNSS receiver model.

Since the accuracy of the 3D environment model and aircraft trajectory are limited, the deterministic multipath model is enhanced by statistical draws associated with several environment uncertainties. This Monte-Carlo analysis is performed for the building positions and orientations in the horizontal plane, their height and materials, as well as the material thicknesses, the ground material and the scene altitude. At each point of a trajectory, this gives the mean and standard deviation of the pseudo-range error. 


\section{ANTENNA MODEL}

In this section, we firstly analyze what should include the antenna model to get realistic multipath simulations. In Fig. 2, we compare the gain patterns obtained with Feko for a L1 patch antenna in the presence of either a finite-size ground plane, a limited fuselage around the antenna, or complete Airbus aircraft models (models A and B).

From these results, we conclude that the simulation model has to include the complete fuselage to achieve enough precision at low elevation angles, where most multipath typically arrive. Besides, the type of aircraft does not affect significantly the radiation pattern. Indeed, models A and B yield similar results though they correspond to different aircraft.

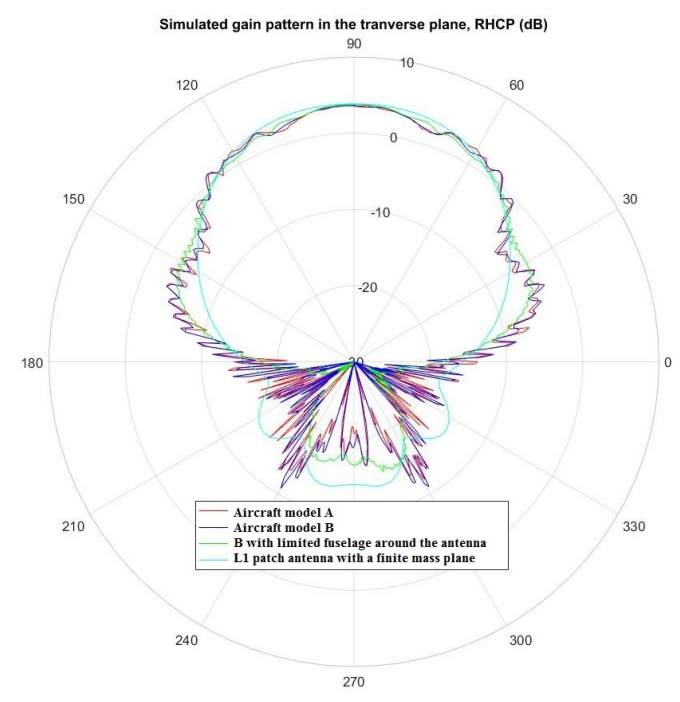

Fig. 2: Simulated L1 antenna gain patterns (dBi) in the vertical plane transverse to the aircraft

We now include the phase and group delay patterns of the receiving antenna. From these patterns that are computed with Feko, supplementary phase shift and group delay are added to each multipath. As an illustration the antenna differential delay pattern for model A is shown in Fig 3. The differential group delay is defined in each direction as the group delay malus the mean group delay at $5^{\circ}$ elevation. At azimuths $90^{\circ}$ and $270^{\circ}$, the influence of the wings can be observed. For elevations from $20^{\circ}$ to $90^{\circ}$, the impact of the vertical stabilizer is visible.

\section{IMPACT OF THE PHASE AND GROUP DELAY PATTERNS ON PSEUDO-RANGE ERRORS}

To highlight the impact of the antenna phase and group delay patterns on the pseudo-range, three configurations are studied for a trajectory at Blagnac airport. The first one corresponds to an ideal isotropic L1 antenna. The two others correspond to model B with and without the phase and group delay patterns. We show in Tab. I the results for a 368 points trajectory with 13 Monte-Carlo draws. The isotropic antenna model provides high mean and standard deviation pseudorange errors due to the ground overvaluation. Indeed lowelevation angles multipath are not attenuated as with a realistic

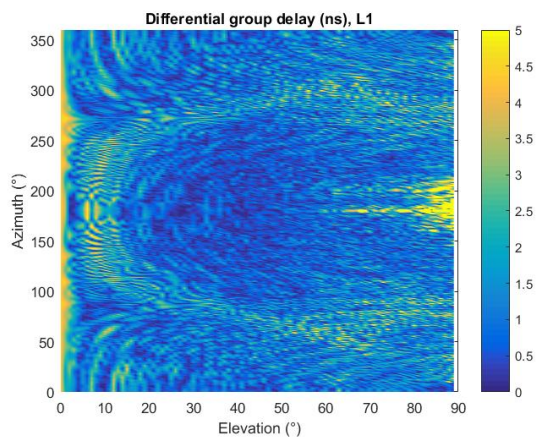

Fig. 3: Simulated differential group delay for a patch antenna with model B aircraft at L1 frequency

antenna. With phase and group delay variations, the multipath effects are less important than with phase variations only.

\begin{tabular}{l|l|l}
\hline Antenna model & Mean $(\mathrm{m})$ & Std $(\mathrm{m})$ \\
\hline Isotropic & 0.169 & 0.862 \\
With phase pattern & -0.034 & 0.036 \\
With phase and group delay patterns & -0.015 & 0.028
\end{tabular}

TABLE I: Simulation results for a Model B aircraft on Blagnac airport along a 368 points trajectory

\section{CONClusion}

In this article, the impact of the gain, phase and groupdelay patterns of the receiver antenna in pseudo-range errors has been discussed from simulation results. We have shown that the antenna simulation should include an aircraft model and that an isotropic antenna may be too conservative.

\section{REFERENCES}

[1] A. Chen, A. Chabory, A.C. Escher, C. Macabiau, "Development of a GPS Deterministic Multipath Simulator for an Efficient Computation of the Positioning Errors," in Proc. ION GNSS, Savannah (USA), Sept. 2009

[2] A. Chen, A. Chabory, A.-C. Escher, C. Macabiau. "Hybrid deterministicstatistical GPS multipath simulator for airport navigation", CECom 2010, 20th International Conference on Applied Electromagnetics and Communications, Sep 2010, Dubrovnik, pp 1-4, 2010 